\title{
HOW SHOULD FREE WILL SKEPTICS PURSUE LEGAL CHANGE?
}

\author{
Marcelo Fischborn \\ This paper is published in Neuroethics and is available at Springer via \\ http://dx.doi.org/10.1007/s12152-017-9333-8
}

\begin{abstract}
Free will skepticism is the view that people never truly deserve to be praised, blamed, or punished for what they do. One challenge free will skeptics face is to explain how criminality could be dealt with given their skepticism. This paper critically examines the prospects of implementing legal changes concerning crime and punishment derived from the free will skeptical views developed by Derk Pereboom and Gregg Caruso. One central aspect of the changes their views require is a concern for reducing the severity of current forms of punishment. The paper considers two strategies for pursuing such a reduction. By taking into account evidence from the psychology of belief in free will and desire to punish, it is argued that a strategy aiming at a reduction of people's natural desire to punish criminals can be successful if capable of providing alternatives to current forms of punishment satisfying three properties: they must be less harmful than current forms of punishment, more effective in preventing crime, and incompatible with current forms of punishment.
\end{abstract}

Keywords: free will skepticism; punishment; criminal behavior; public opinion; criminal law

\section{Introduction}

Theorists who doubt that people have free will often show a concern for the practical implications of their views. The concern derives from the fact that free will is usually thought to be a necessary condition for things such as moral and legal responsibility, desert, and punishment. Derk Pereboom $(2001,2014)$ illustrates this pattern well. While he defends the view that people are never free in a sense that would make them truly deserve to be praised, blamed, or punished for their actions - a view he calls 'free will skepticism' - he also puts forth a fairly elaborate account of how crime could be dealt with given such skepticism. ${ }^{1}$ His account includes two main parts. One is the rejection of retributivistic justifications of punishment that appeal to the claim that criminals should be punished because they deserve it. The other is a

1 Although this paper focuses on Pereboom's project, I will also consider the way Caruso (2016) further develops it. Other free will skeptic proposals include the ones by Corrado (2013), Greene and Cohen (2004) and Vilhauer (2013). 
proposal of independently acceptable ways to prevent crime that avoid inflicting harm as much as possible. In synthesis, Pereboom's project begins with free will skepticism and goes all the way down to the claim that current punishment practices (and criminal law, more generally) should be modified.

The question I want to answer in this paper is the following: Were theorists to become convinced that no one has the free will that would be required for making punishment ever deserved, how should the relevant legal changes be pursued? In asking this question, I intend to contribute with the investigation of the practical viability of a free will skeptic project, but this is not meant to imply that I am endorsing skepticism. Indeed, free will skepticism is far from consensual among theorists, and I will not intervene in this debate here. ${ }^{2}$ But as I will indicate in the end, this investigation has some lessons that can be relevant beyond the scope of free will skepticism.

Below, I begin by describing Pereboom's free will skeptic project in more detail, and the way Gregg Caruso (2016) has extended Pereboom’s project (section 2). I then present and criticize what I call a cognitive strategy for pursuing relevant legal changes (section 3). Finally, I present a more promising, non-cognitive strategy for pursuing legal changes (section 4), and conclude by indicating how non-skeptics may also benefit from the previous reflection (section 5).

\section{Free will skepticism and punishment}

Free will skepticism is the view that no one has the kind of free will that is required for an agent to be morally responsible in what Pereboom calls the 'basic desert sense'. In this sense, responsibility practices are essentially backward-looking. If an agent is responsible in the basic desert sense, then she "would deserve to be blamed or praised just because she has performed the action, given an understanding of its moral status, and not, for example, merely by virtue of consequentialist or contractualist considerations” (Pereboom, 2014, p. 2; see also his 2001). Pereboom's argument for the claim that we do not have the kind of free will that is required for responsibility in the basic desert sense is based on the following premises. First, he rejects event-causal libertarian theories, and argues that free will requires agent-causation (2014, ch. 2). Second, he argues that the claim that we are agents with such causal powers is

2 Among contemporary authors, opposition to free will skepticism comes mainly from proponents of theories that affirm the existence of free will, including libertarians (Kane, 1996), compatibilists (Fischer, 1994; Morse, 2013), and views that combine elements of both compatibilism and libertarianism in different ways (Mele, 1995; Mele, 2006; Vargas, 2013). 
implausible given current physical theories (ch. 3). Finally, Pereboom also rejects compatibilism as a viable alternative on the basis of manipulation arguments (ch. 4). It follows that it is implausible that we have the kind of free will that is required for responsibility in the basic desert sense.

For the purposes of this paper, the most relevant feature of Pereboom's free will skepticism is that it entails that people never deserve, in the basic desert sense, to be punished. If that is true, then no justification of punishment that assumes people deserve it (such as retributivism) can be successful. This is significant because retributivism is one of the leading alternatives when it comes to the justification of punishment, and also because current criminal justice systems seem to have a significant retributivistic character. Bedau and Kelly (2015), for example, argue that the very notion of punishment is 'inherently retributive'. As a consequence, describing acceptable alternative ways of dealing with criminal behavior is a pressing task for a free will skeptic.

An often considered alternative to retributivism is consequentialism. Purely consequentialist justifications of punishment avoid claims about what an agent deserves, and instead focus on its possible positive consequences, such as deterrence or incapacitation. This alternative has been embraced by some skeptics about the existence of free will (e.g. Greene and Cohen, 2014). On their view, increasing disbelief in free will would eventually motivate a transition from retributivistically-oriented forms of punishment to more consequentialist ones. But Pereboom rejects this move. Although he grants that consequentialism is consistent with free will skepticism, he argues that it faces serious ethical objections, including an inability to offer a principled rejection of patently problematic possibilities—such as punishing an innocent or punishing someone much more harshly than it would seem fair-if they happen to be conductive to the best consequences overall (see Pereboom, 2014, pp. 163-165). That is why Pereboom's proposal involves neither retributivism nor pure consequentialism.

As a viable alternative, Pereboom seeks to justify measures whose focus is on crime prevention and not on the response to crime that has already occurred. Here is a summary of his view:

If the free will skeptic is right, criminal punishment for retributive reasons is ruled out. [...] But a theory of crime prevention that would be acceptable whether or not the skeptic is right can be developed by analogy with our rationale for quarantining carriers of dangerous diseases. The core idea is that the right to harm in self-defense and defense of others justifies incapacitating the criminally dangerous with the minimum harm required for adequate protection. [...] The free will skeptic would also endorse measures for reducing crime that aim at altering social conditions, such as improving education, increasing opportunities for fulfilling employment, and enhancing care for mentally ill. 
(Pereboom, 2014, pp. 173-174; see also 2001, ch. 6)

As we can infer from this passage, Pereboom's proposal has two main components. One component consists in the rejection of punishment for retributive reasons. ${ }^{3}$ This entails that, if current criminal justice systems do rely on retributive considerations to some extent, they need to be revised. A second component focuses on crime prevention and has two aspects. One aspect is the justification of measures to prevent imminent crime through the incapacitation of likely criminals with the minimum harm needed (e.g. detention) based on the right to harm in selfdefense. According to Pereboom, there are various requirements for a proper implementation of this aspect of the preventive component. For example, the right to liberty, the concern that people will be used merely as means, and the possibility of misuse by the state should be seriously considered (2014, p. 170). Also, preventive detention would require the availability of very accurate, reliable, and non-invasive methods for detecting the likelihood of criminal behavior, as well as a concern for the wellbeing of, and an effort to rehabilitate detained individuals (pp. 170-171). The other aspect of the preventive component proposes measures that aim at preventing people from becoming likely criminals in the first place, and include the improvement of social and health conditions.

Pereboom's proposal has been defended and extended by Gregg Caruso (2016), and by Pereboom and Caruso (forthcoming) in collaboration. Caruso (2016) justifies the free will skeptic approach to criminality within the framework of public health ethics. He calls the resulting model a 'public health-quarantine model'. One of the innovations in this model is the claim that free will skeptics not just can adopt measures for crime prevention-as Pereboom originally suggested — but should prioritize doing so (2016, p. 31). As he says:

[Pereboom's] quarantine analogy is narrowly focused on justifying the incapacitation of dangerous criminals. [...] The public health-quarantine model justifies the incapacitation of dangerous criminals but the primary focus should always be on preventing crime from occurring in the first place by addressing the systemic causes of crime. Prevention is always preferable to incapacitation. (2016, pp. 35-36)

Caruso's model, therefore, includes at least two new elements: it goes beyond Pereboom's quarantine analogy when it comes to the justification of responses to crime; and it emphasizes prevention over incapacitation as the preferred form of response.

For the purposes of this paper, it matters to identify a group of legal changes that is common to both Pereboom's and Caruso's proposals. The group of changes I have in mind in-

3 Sometimes, Pereboom seems to reject punishment completely, and not just punishment on retributive grounds (see 2014, p. 165). 
cludes only those that properly depend on, or are required by, their free will skepticism. Free will skepticism, for example, entails that an individual who has committed a crime does not deserve any punishment in response. It also entails that, at the very least, we should be concerned about the fact that most societies currently assign punishment in response to crime. But it does not follow from the thesis that we lack the kind of free will that would make punishment ever deserved that we should adopt any of the preventive measures Pereboom and Caruso describe. Pereboom himself describes some of those measures as "acceptable whether or not the skeptic is right” (emphasis added), which suggests that even non-skeptics might be willing to support them. And even though Caruso says his model requires active steps to prevent crime, such requirement derives not from his skepticism but from the public health ethics he also adopts. What is left as an essentially free will skeptic demand for legal change is a concern for reducing as much as possible the amount of harm to be inflicted upon those who have committed crimes. It might be suggested that free will skepticism requires the actual reduction of such harm, but Pereboom's claim (which Caruso also accepts) that "the minimum harm required for adequate protection" should be used seems consistent with the possibility that current forms of punishment did already reach that minimum. Consider, for example, incarceration as a punishment. A free will skeptic should propose at least a reduction in incarceration duration (reduction understood as consistent with elimination) if it can be shown that shorter incarceration sentences are enough for adequate protection. ${ }^{4}$ Therefore, the best candidate for the sort of legal change free will skepticism requires is a concern for reducing as much as possible the amount of harm to be inflicted upon those who have committed a crime, leaving open the possibility of completely eliminating such harm.

Assume, now, that a convincing case can be made for the claim that a reduction in the harm involved in current forms of punishment is consistent with keeping or increasing the level of protection against damage or violence that individuals within a certain society enjoy. That would mean that a reduction in the severity of current punishment practices is consistent with keeping or increasing the level of protection within that society. The main question for this paper can now be reframed as follows: Given such an assumption, how should a free will skeptic pursue the relevant legal changes, i.e., changes aiming at the reduction of punishment severity within a certain society? In the remainder of this paper, I consider two answers to this question.

4 Of course, on the same condition, the free will skeptic should also propose the reduction of other harms often associated with imprisonment (e.g., prison violence, and prisoner mistreatment). 


\section{Pursuing legal change: A cognitive strategy}

How should a free will skeptic pursue legal changes aiming at the reduction of punishment severity within a given society? In this section, I begin by motivating an important constraint to be taken into account when assessing the prospects of different strategies for pursuing legal change. Then I describe a first obvious strategy available to the free will skeptic, and explain why I think it is unpromising. A more promising alternative will be presented in section 4 .

A desiderata for any strategy for legal change is that it can make the changes proposed acceptable for a substantial part of a given society's members. The reason for this constraint on strategies for legal change is that I am interested in assessing the prospects of such strategies in democratic societies. In democracies, relevant changes in the law usually need to be sanctioned by a majority of legislators. Also, the wider population itself has to elect those representatives in the first place. Therefore, it is hard to see how new laws could be sanctioned without the wider population itself endorsing to some extent the views of those candidates who defend the legal changes under consideration. In addition, even if changes could come to be implemented without the agreement of most people, a huge discrepancy between what the population believes and desires and what the legal system provides might pose a threat to the system's legitimacy (see, e.g., de Keijser \& Elffers, 2009, for an analysis of this problem in the context of The Netherlands). It follows that, other things being equal, free will skeptics interested in implementing the legal changes recommended by their views should favor a strategy that has a better chance of gaining popular adherence.

A first possible strategy for pursuing legal change can be easily derived from Pereboom's and Caruso's free will skeptic projects. Just as free will skeptics themselves propose legal changes because they believe no one has free will, legal change could be pursued by trying to convince the larger population that no one has free will. I will call this a cognitive strategy because it has belief in free will as a target in its pursuit of legal change. This does not seem a promising alternative, though.

First, people’s current beliefs about free will, desert, and punishment are in clear opposition to free will skepticism. Studies on people's beliefs about free will indicate that they are strong (Nadelhoffer et al., 2014, p. 38) and hard to manipulate (Schooler et al., 2015). Interestingly, many of the attempts to decrease belief in free will involve real or fictitious quotes from scientists saying that free will does not exist or is an illusion (see Vohs \& Schooler, 2008, p. 50; Schooler et al., 2015, pp. 75-77). And even when experimental manipulation is 
statistically significant, belief in free will remains considerably strong. For example, Monroe, Brady and Malle (2016, study 1) successfully decreased belief in free will from 5.03 (SD = $1.17 ; 1$ = 'strongly disagree', 7 = 'strongly agree') to 4.77 (SD = 1.25). If we take into account the fact that statements used to assess belief in free will included such strong claims as 'People always have free will' (see Nadelhoffer et al., 2014, p. 34 for the scale used in the study), it is fair to conclude that even participants who had their beliefs successfully decreased were far from becoming free will skeptics. Studies also confirm that people take punishment to be appropriate in a variety of contexts. For another item in Nadelhoffer et al.'s scale (2014, p. 38)—saying that "People who harm others deserve to be punished even if punishing them will not produce any positive benefits to either the offender or society-e.g., rehabilitation, deterring other would-be offenders, etc."-responses averaged 5.37 (SD = 1.46; 1 = 'strongly disagree', 7 = 'strongly agree'; $\mathrm{n}=330$; sample from the United States population). These results indicate that most people in this population are likely to disagree with the skeptic's denial of free will and its consequences for punishment. Moreover, there is some evidence that patterns in beliefs about free will and attitudes toward punishment are similar across different cultures. Sarkissian et al. (2010) found similarities in belies about free will across Western and Eastern countries. And Santin et al. (manuscript) found evidence of the transcultural validity of Nadelhoffer et al.'s scale in a Brazilian sample. Therefore, it is at least a worth considering hypothesis that belief in free will and support for punishment are similarly strong and robust across different cultures. ${ }^{5}$

Second, belief in free will and desire to punish are not independent. Rather, belief in the existence of free will and in the appropriateness of punishing criminals seem to be part of a natural and widespread strategy people adopt with the aim of repelling undesirable behavior. In a series of studies by Clark et al. (2014), people showed stronger belief in free will after exposure to crime and immoral behavior. This effect was found to be mediated by a stronger desire to punish the authors of those actions. These results suggest that confidence in the effectivity of alternative ways of reducing crime might be a prerequisite for reducing belief in free will and then getting enough support for changes in more traditional forms of punishment. Therefore, it might be that a free will skeptic approach to crime can only be implemented if it can ensure the efficacy of alternative ways of reducing crime.

5 It is also a worth considering possibility that the relation between belief in free will and desire to punish indicated in the next paragraph is similar across cultures. It goes without saying that, were these aspects of belief in free will and attitudes toward punishment to be peculiar to some cultures, the overall conclusions of this paper should be relativized accordingly. 
Third, there is some chance that less severe punishment may contribute to increase criminality, which might end up reinforcing belief in free will. It is accepted, for example, that punishment has preventive effects on crime. After critically reviewing studies on the preventive effects of punishment, Suhling and Greve (2009, p. 420) agree that "despite many methodological problems and often inconsistent results, a crime-preventive effect of the existence of the criminal justice system cannot be denied”. It has also been pointed out that deterrence is somewhat correlated with the severity of punishment-although the connection is weaker than that between deterrence and punishment certainty (see von Hirsch et al., 1999; Friesen, 2012; but see also Doob \&Webster, 2003). These effects of punishment are also present in laypersons' views. In another item in Nadelhoffer et al.'s study—saying that “People who perform harmful actions ought to be punished so that other potential offenders are deterred from committing similar harmful actions”-the responses averaged 5.78 (SD = 1.2), indicating again a substantial agreement with the statement. Thus, insofar as free will skepticism requires an attempt to reduce punishment severity, the risk of increasing crime might actually reinforce belief in the existence of free will and opposition to a free will skeptic project.

On the three aspects considered, therefore, a cognitive strategy for legal change having belief in free will as a main target looks unpromising. Belief in free will is currently strong, to begin with, and the way belief in free will relates to other beliefs and desires makes unlikely that it will get weaker without (at the very least) a significant reduction in crime. Free will skeptics, therefore, need a better strategy for pursuing relevant legal changes.

\section{A non-cognitive strategy}

One of the challenges for the cognitive strategy just described is that crime can trigger a desire to punish which has been shown to reinforce belief in free will. This sets the stage for considering an alternative strategy focusing on the desire to punish. A widespread reduction in people's desire to punish might, simultaneously, favor two central goals that free will skeptics may have. First, a reduced desire to punish would make support for a reduction in punishment severity easier to achieve. Second, a reduced desire to punish might contribute to a reduction in the strength of people's belief in free will. Because the main target of this strategy for legal change is a desire, I call it a non-cognitive strategy. ${ }^{6}$

6 It should not be assumed that the non-cognitive strategy needs to exclude the aim of convincing people that they lack free will. In this sense, the cognitive and non-cognitive strategies may be taken as two components that may or may not be combined in a real attempt to implement legal recommendations derived from free will skepticism. 
Is there any plausible way of reducing the desire to punish available for the free will skeptic? Studies on people's preferences concerning different sorts of policies on crime provide an interesting starting point. McCorkle (1993) found that people tend to favor both punitive and rehabilitative policies when their combination is possible. In another study, Baker et al. (2015) found that rehabilitation policies are preferred to punitive ones when people are forced to choose for only one of them. These results suggest some further constraints on how punishment severity can be successfully reduced. First, in accordance with the free will skeptic project, they must be less harmful than current practices. Second, they must be more effective in reducing crime; otherwise crime itself could reinforce a desire for punishment. And third, they must be incompatible with current forms of punishment because otherwise people might continue to support current forms of punishment alongside other measures. Should we become convinced of the existence of alternatives satisfying these three properties, I think it is a reasonable prediction that our natural desire to punish criminals would become weaker. Of course this is a prediction that needs further empirical investigation, but it seems our best guess given the evidence available so far.

Earlier in the paper I have distinguished between those legal changes that are entailed by free will skepticism (reduction in punishment severity) and those that are not (preventive measures). The relevance of this distinction can now be better appreciated and qualified. Only the legal changes derived from free will skepticism are incompatible with current punitive responses to crime, on the assumption that less harmful practices can ensure an adequate level of social protection. Hence only measures involving a reduction in punishment severity would be considered as a replacement for current practices. Pereboom's and Caruso's preventive measures, on their turn, are strictly consistent with non-skeptical views, and thus could be more easily supported by the public, although not instead of current practices.

As previously mentioned, the empirical studies on belief in free will and desire to punish suggest that a reduction in crime may be a necessary condition for reducing the desire to punish criminals. This suggests some qualification regarding the points made in the previous paragraph. For if measures for crime prevention are successfully implemented, one can also expect an overall reduction in desire to punish and belief in free will. Success in prevention, therefore - even if not conceptually required by free will skepticism itself - may be contingently central for achieving some of the free will skeptic's goals. In other words, Pereboom and Caruso are right to emphasize preventive measures, although maybe for reasons not fully 
understood so far. On the other hand, those legal changes that free will skepticism strictly requires concern what the responses to actual crime should be. For this reason, even if crime prevention can reduce desire to punish on a general level, it does not follow that the specific desire to punish that arises after a particular crime is considered will also decrease. The question of whether free will skeptics should pursue the non-cognitive strategy, therefore, can only be answered by investigating the existence of alternatives involving a reduction in punishment severity that can be simultaneously successful in the prevention of crime.

Are there any good reasons to believe that such alternatives can be found? Physical punishment of children, although not a part of the criminal justice system itself, provides an interesting case for reflection. Research indicates that the practice of physically punishing children is widespread across the globe (see, e.g., Kish \& Newcombe, 2015; Global Initiative, 2016). It has been suggested that parents' beliefs about its necessity for proper education and unharmfulness are among the possible causes of parental use of physical punishment (Kish \& Newcombe, 2015). And yet, several studies have shown that physical punishment of children is associated with undesirable outcomes such as aggressiveness, antisocial behavior and psychological problems, among many others (Gershoff, 2002; Afifi et al., 2006; Durrant \& Ensom, 2012). For these reasons, there have been initiatives to end up with the practice of physically punishing children, which have led many countries to prohibit its use. By 1990, four countries prohibited all corporal punishment of children. The number increased to eleven by 2000, to thirty-four by 2011, and is currently forty-seven (see Global Initiative, 2015; Durrant \& Ensom, 2012, p. 1373).

Without overlooking important differences, the case of the physical punishment of children provides a model for thinking about alternatives to current forms of legal punishment. First, there is a convincing case for reducing the severity or harm involved in punishing children-actually, there is a convincing case for abolishing the practice of harming children in the process of educating them. Second, the evidence suggests that a non-punitive education is more effective in preventing certain undesirable attitudes, including aggressiveness. And third, the alternatives proposed are incompatible with preserving old punitive practices because physical punishment itself is identified as a causal factor for those negative outcomes. Therefore, the case for abolishing the physical punishment of children satisfies all of the three properties previously identified as necessary for a successful reduction in the severity of current forms of legal punishment. And if this alternative works in the case of children, it is an 
open possibility that something analogous could work for adults and make the non-cognitive strategy a promising one.

A challenge for the implementation of legal changes of the sort free will skepticism requires can now be more precisely stated. As in the case of children, what needs to be shown is that alternative ways of responding to criminals can be more effective in crime prevention in virtue of being less harmful. In other words, support for reduction in punishment severity can be expected if more severe punishment actually contributes to higher recidivism rates. A worth considering possibility is that some policies for crime prevention might turn out to work better in the absence of certain harmful aspects associated with punishment. For example, recidivism rates have been shown to be higher in overcrowded prisons (Farrington \& Nuttall, 1980; Haney, 2006; Haney, 2015) and lower when education programs are available (Kim \& Clark, 2013; Sellers, 2015). But these possibilities still fall short of showing that, say, shorter sentences would lead to lower recidivism rates. And, finally, an additional difficulty free will skeptics need to address is the unresolved issue about the relation between punishment severity and crime rates (von Hirsch et al., 1999; Friesen, 2012; Doob \&Webster, 2003). These are all empirical questions that free will skeptics willing to use the non-cognitive strategy in an attempt to implement the legal changes required by their skepticism may need to address.

\section{Concluding remarks}

Free will skeptics such as Pereboom and Caruso argue that, even if humans do not have free will in the basic desert sense, we still have sufficient resources to deal with criminal behavior. This paper did not dispute the truth of this sufficiency claim if understood on purely conceptual or normative grounds. But I did put forth arguments that describe practical challenges that an attempt to implement this sort of proposal is likely to face. By considering how a central tenet derived from free will skepticism-a concern for reducing punishment severity as much as possible-could come to be implemented, I described two strategies for pursuing the relevant legal changes, as well their respective requirements and challenges. If my arguments are on the right track, the best strategy for changing the law in ways that reduce punishment severity is by seeking a reduction of people's natural desire to punish criminals. But this can only be achieved by finding alternatives to current punishment practices that cannot be implemented alongside current practices and that are more effective in preventing crime. If these 
conditions can be met, the prospects are high that a public support for the implementation of the relevant legal changes can be achieved.

As a final thought, I would like to emphasize that the concerns of this paper can be relevant beyond the scope of free will skepticism. As a first example, free will agnosticism, the view according to which no one knows whether humans have free will, has been said to have implications for punishment that are similar to those of Pereboom's account (Kearns, 2015, p. 249, n. 8). Second, practices of punishment currently accepted in some societies are sometimes claimed to be excessive. For example, some theorists consider capital punishment excessive on the argument that target criminals' history often include factors that reduce culpability (Steiker, 2011, p. 444-446). A third possibility would be to argue that punishment severity should be reduced in some cases even if deserved. One way to defend this is by distinguishing the conditions for an amount of punishment to be deserved from the conditions for an amount of punishment to be mandatory (see, Hart, 2008, p. 236; Steiker, 2011, p. 442; Zimmerman, 2015, p. 55). It is open for someone who makes this distinction to say that matters beyond desert-such as analyses of the effects or cost-effectiviness of current forms of punishment (see, e.g., Kleiman, 2009; Clear and Frost, 2014)—favor reducing punishment severity even if criminals deserve what is currently prescribed. The challenges and possibilities for the implementation of legal changes of the sort discussed in this paper can, therefore, be relevant far beyond the scope of free will skepticism. In fact, they concern any proposal that has a reduction in punishment severity as a consequence. ${ }^{7}$

\section{References}

Afifi, T. O.; Brownridge, D. A.; Cox, B. J. and Sareen, J. (2006). "Physical punishment, child abuse and psychiatric disorders”, Child Abuse and Neglect 30: 1093-1103.

Baker, T.; Metcalfe, C. F.; Berenblum, T.; Aviv, G. and Gertz, M. (2015). "Examining public preferences for the allocation of resources to rehabilitative versus punitive crime policies", Criminal Justice Policy Review 26: 448-462.

Bedau, H. A. and Kelly, E. (2015). “Punishment”. In: Zalta, E. N. (Ed.), The Stanford Encyclopedia of Philosophy, .

7 This work has been financially supported by Coordenação de Aperfeiçoamento de Pessoal de Nível Superior (CAPES) [BEX 4789/15-6] and by Fulbright Brasil. For comments on earlier versions of this paper, I would like to thank Lieke Asma, Gilberto Gomes, Stephen Kearns, Alfred Mele, Leonardo Ribeiro, Frank Sautter, Rogério Severo, Silvio Vasconcellos, and Flavio Williges. I also thank the audiences of the Writing Group at Florida State University, the 2016 UF/FSU Graduate Philosophy Conference, and the 3rd Workshop on Naturalism. 
Caruso, G. D. (2016). "Free will skepticism and criminal behavior: A public health-quarantine model”, Southwest Philosophy Review 32: 25-48.

Clark, C. J.; Luguri, J. B.; Ditto, P. H.; Knobe, J.; Shariff, A. F. and Baumeister, R. F. (2014). "Free to punish: A motivated account of free will belief", Journal of Personality and Social Psychology 106: 501-513.

Clear, T. R. and Frost, N. A. (2014). The punishment imperative: The rise and failure of mass incarceration in America. New York: New York University Press.

Corrado, M. L. (2013). "Why do we resist hard incompatibilism? Thoughts on freedom and punishment”. In: Nadelhoffer, T. A. (Ed.), The future of punishment, pp. 109-104. Oxford: Oxford University Press.

Doob, A. N. and Webster, C. M. (2003). "Sentence severity and crime: Accepting the null hypothesis”, Crime and Justice 30: 143-195.

Durrant, J. and Ensom, R. (2012). "Physical punishment of children: lessons from 20 years of research”, Canadian Medical Association Journal 184: 1373-1377.

Farrington, D. P. and Nuttall, C. P. (1980). "Prison size, overcrowding, prison violence, and recidivism”, Journal of Criminal Justice 8: 221-231.

Fischer, J. M. (1994). The metaphysics of free will. Oxford: Blackwell Publishers.

Friesen, L. (2012). "Certainty of punishment versus severity of punishment: An experimental investigation”, Southern Economic Journal 79: 399-421.

Gershoff, E. T. (2002). "Corporal punishment by parents and associated child behaviors and experiences: a meta-analytic and theoretical review”, Psychological Bulletin 128: 539-579.

Greene, J. and Cohen, J. (2004). "For the law, neuroscience changes nothing and everything”, Philosophical Transactions of the Royal Society of London 359: 1775-1785.

Haney, C. (2006). “The wages of prison overcrowding: Harmful psychological consequences and dysfunctional correctional reactions", Washington University Journal of Law \& Policy 22: 265-293.

Haney, C. (2015). “Prison overcrowding”. In: Cutler, B. L. \& Zapf, P. A. (Ed.), APA handbook of forensic psychology (Criminal investigation, adjudication, and sentencing outcomes), pp. 415-436. Washington, DC: American Psychological Association.

Hart, H. L. A. (2008). Punishment and responsibility: Essays in the philosophy of law (Second Edition). Oxford: Oxford University Press.

von Hirsch, A.; Bottoms, A. E.; Burney, E. and Wikstrom, P.-O. (1999). Criminal deterrence and sentence severity: An analysis of recent research. Oxford: Hart Publishing.

Initiative (2015). “Global initiative to end all corporal punishment of children”, http://www.endcorporalpunishment.org/.

Kane, R. (1996). The significance of free will. Oxford: Oxford University Press.

Kearns, S. (2015). “Free will agnosticism”, Noûs 49: 235-252.

de Keijser, J. W. and Elffers, H. (2009). "Punitive public attitudes: A threat to the legitimacy of the criminal justice system?”. In: Oswald, M. E.; Bieneck, S. \& Hupfeld-Heinemann, J. 
(Ed.), Social psychology of punishment of crime, pp. 55-74. Chichester: Wiley-Blackwell.

Kim, R. H. and Clark, D. (2013). “The effect of prison-based college education programs on recidivism: Propensity Score Matching approach”, Journal of Criminal Justice 41: 196204.

Kish, A. M. and Newcombe, P. A. (2015). ““'Smacking never hurt me!” Identifying myths surrounding the use of corporal punishment”, Personality and Individual Differences 87: 121-129.

Kleiman, M. A. R. (2009). When brute force fails: How to have less crime and less punishment. Princeton: Princeton University Press.

McCorkle, R. C. (1993). "Research note: Punish and rehabilitate? Public attitudes toward six common crimes”, Crime \& Delinquency 39: 240-252.

Mele, A. (2006). Free will and luck. Oxford University Press: Oxford University Press.

Mele, A. R. (1995). Autonomous agents: From self-control to autonomy. Oxford: Oxford University Press.

Monroe, A. E.; Brady, G. and Malle, B. F. (2016). “This isn’t the free will worth looking for: General free will beliefs do not influence moral judgments; agent-specific choice ascriptions do", Social Psychological and Personality Science : 1-9.

Morse, S. J. (2013). “Compatibilist criminal law”. In: Nadelhoffer, T. A. (Ed.), The future of punishment, pp. 107-131. Oxford: Oxford University Press.

Nadelhoffer, T.; Shepard, J.; Nahmias, E.; Sripada, C. and Ross, L. T. (2014). "The free will inventory: Measuring beliefs about agency and responsibility”, Consciousness and Cognition 25: 27-41.

Pereboom, D. (2001). Living without free will. Cambridge: Cambridge University Press.

Pereboom, D. (2014). Free will, agency, and meaning in life. New York: Oxford University Press.

Pereboom, D. and Caruso, G. D. (forthcoming). "Hard-incompatibilist existentialism:Neuroscience, punishment, and meaning in life”. In: Caruso, G. D. \& Flanagan, O. (Ed.), Neuroexistentialism: Meaning, morals, and purpose in the age of neuroscience, pp. . : Oxford University Press.

Santin, T. R.; Vilanova, F.; Costa, Â. B.; Tocchetto, D. G.; Nadelhoffer, T. and Koller, S. H. (manuscript). "Evidências de validade do Inventário do Livre-Arbítrio (ILA) para a população brasileira”, .

Sarkissian, H.; Chatterjee, A.; de Brigard, F.; Knobe, J.; Nichols, S. and Sirker, S. (2010). "Is belief in free will a cultural universal?”, Mind \& Language 25: 346-358.

Schooler, J.; Nadelhoffer, T.; Nahmias, E. and Vohs, K. D. (2015). “Measuring and manipulating beliefs and behaviors associated with free will: The good, the bad, and the ugly”. In: Mele, A. R. (Ed.), Surrounding free will: Philosophy, Psychology, Neuroscience, pp. 72-94. New York: Oxford University Press.

Sellers, M. P. (2015). “Online learning and recidivism rates”, International Journal of Leadership in Education . 
Steiker, C. (2011). “The death penalty and deontology”. In: Deigh, J. \& Dolinko, D. (Ed.), The Oxford handbook of the philosophy of the criminal law, pp. 441-466. New York: Oxford University Press.

Suhling, S. and Greve, W. (2009). “The consequences of legal punishment”. In: Oswald, M. E.; Bieneck, S. \& Hupfeld-Heinemann, J. (Ed.), Social psychology of punishment of crime, pp. 405-426. Chichester: Wiley-Blackwell.

Vargas, M. (2013). Building better beings: A theory of moral responsibility. Oxford: Oxford University Press.

Vilhauer, B. (2013). "Persons, punishment, and free will skepticism”, Philosophical Studies 162: $143-163$.

Vohs, K. D. and Schooler, J. W. (2008). "The value of believing in free will: Encouraging a belief in determinism Increases cheating”, Psychological Science 19: 49-54.

Zimmerman, M. (2015). “Varieties of moral responsibility”. In: Clarke, R.; McKenna, M. \& Smith, A. M. (Ed.), The nature of moral responsibility: New essays, pp. 45-64. New York: Oxford University Press. 